\title{
A FORMAÇÃO CONTINUADA PARA GESTORES DA EDUCAÇÃO BÁSICA E A DEMANDA DO COTIDIANO ESCOLAR: UMA ANÁLISE NO ÂMBITO DAS POLÍTICAS PÚBLICAS ${ }^{1}$
}

\author{
LA FORMACIÓN CONTINUA PARA DIRECTIVOS DE EDUCACIÓN \\ BÁSICA Y EXIGIR LA ESCUELA TODOS LOS DÍAS: UN ANÁLISIS EN EL \\ CONTEXTO DE LAS POLÍTICAS PÚBLICAS
}

THE CONTINUED TRAINING FOR MANAGERS OF BASIC EDUCATION AND THE DEMAND OF THE SCHOOL DAILY: AN ANALYSIS IN THE SCOPE OF PUBLIC POLICIES

\author{
Evally Solaine de Souza RODRIGUES ${ }^{2}$ \\ Maria das Graças Fernandes de Amorim dos REIS ${ }^{3}$ \\ Maria Alice de Miranda ARANDA ${ }^{4}$
}

RESUMO: As transformações políticas e econômicas que permearam o século XX tornou o conhecimento como força produtiva, consequentemente, as exigências sobre a escola, bem como sua gestão se multiplicaram. Desse modo, esta pesquisa de abordagem qualitativa consiste em relacionar as políticas de formação continuada de gestores da Educação Básica com o atendimento às demandas do cotidiano escolar. Para a elaboração desta, recorreu-se a pesquisa bibliográfica, documental e entrevistas semiestruturadas com três gestores escolares e um gestor educacional de um munícipio do Sul do estado de Mato Grosso do Sul. Ao final, verificou-se que há impasses entre a efetivação das políticas de formação continuada de gestores e o atendimento da demanda do cotidiano escolar.

PALAVRAS-CHAVE: Gestão escolar. Formação continuada. Políticas educacionais.

RESUMEN: Las transformaciones politicas y económicas que han impregnado el siglo $X X$ tiene el conocimiento como fuerza productiva, en consecuencia, las demandas de la escuela y su gestión se han multiplicado. Por lo tanto, esta investigación cualitativa es relacionar las políticas de educación continua administradores de la educación básica para satisfacer las exigencias de la vida cotidiana escolar. Para producir esto, se utilizó la investigación bibliográfica, documental y entrevistas semiestructuradas con tres directores de escuela y director de educación de un municipio en el estado de Mato

\footnotetext{
${ }^{1}$ Pesquisa financiada pela Fundação de Apoio ao Desenvolvimento do Ensino, Ciência e Tecnologia do Estado de Mato Grosso do Sul (FUNDECT).

${ }^{2}$ Mestranda em Educação, na linha de Políticas Públicas e Gestão da Educação, pelo Programa de Pósgraduação da Universidade Federal de Mato Grosso do Sul (UFGD). E-mail: evallyrodrigues@ gmail.com ${ }^{3}$ Doutora em Educação pela Universidade Federal de São Carlos (UFSCar) e Professora do curso de Pedagogia da Universidade Federal de Mato Grosso do Sul (UFMS), campus de Naviraí-MS. E-mail: gmgrg46@gmail.com

${ }^{4}$ Doutora em Educação pela Universidade Federal de Mato Grosso do Sul. Professora do Programa de Pós-Graduação em Educação - Mestrado e Doutorado - na Universidade Federal da Grande Dourados UFGD. E-mail: mariaaranda@ufgd.edu.br
} 
Grosso do Sul. Al final, se encontró que hay puntos muertos entre la eficacia de continua de políticas de educación y satisfacer la demanda de la vida escolar diaria.

PALAVRAS-CLAVE: Gestión de la escuela. Formación continua. Políticas educativas.

ABSTRACT: The political and economic transformations that permeated the twentieth century made knowledge as a productive force, consequently the demands on the school as well as its management have multiplied. Thus, this research of qualitative approach consists in relating the policies of continuous training of managers of Basic Education with the attendance to the demands of school everyday. For the elaboration of this one, we resorted to bibliographical research, documentary and semi-structured interviews with three school managers and an educational manager from a municipality in the south of the state of Mato Grosso do Sul. In the end, it was verified that there are impasses between the effectiveness of the policies of continuous training of managers and the attendance of the demand of the scholastic quotidian.

KEYWORDS: School management. Continuing Education. Educational policies.

\section{Introdução}

Diante das transformações políticas e econômicas ocorridas no Brasil e no mundo, o conhecimento tornou-se força produtiva direta e às instituições escolares incidiu a obrigação de formar o cidadão adequado aos princípios dessa nova sociedade. Mediante esse contexto, as exigências sobre a gestão escolar se multiplicaram e recaiu sobre o cargo de diretor o acúmulo de atividades.

Nesse sentido autores como Dias (2004), Luck (2000; 2001), Machado (2000), sinalizam a relevância das atividades inerentes ao cargo de diretor escolar para o bom desempenho das instituições de ensino na busca por uma educação de qualidade, bem como as modificações nas incumbências da gestão escolar após a Reforma do Estado (1990) que resulta em uma multiplicidade de atividades inerentes ao cargo de diretor escolar.

Luck (2000) afirma que conforme aumenta a cobrança por uma educação de qualidade, consequentemente, multiplica-se a exigência sobre sua gestão. Desse modo, a autora sinaliza ainda a necessidade e relevância no investimento em formação continuada para essa classe trabalhadora, visto que a formação inicial nem sempre consegue atender as especificidades da função.

Assim sendo, esta pesquisa pretende relacionar se as políticas de formação continuada para gestores escolares tem atendido a demanda do cotidiano escolar. Para a 
realização desta, recorreu-se à abordagem qualitativa, uma vez que diversas informações tratadas estarão envolvendo questões subjetivas, e não podem ser aferidas por meio de dados quantitativos. (Minayo, 1996 apud QUARESMA, 2005).

Com o intuito de manter um equilíbrio entre aspectos empíricos e teóricos, bem como angariar embasamento teórico por meio da apuração das perspectivas que outros autores discutem acerca da temática, foi realizado levantamento bibliográfico, até mesmo porque uma das principais vantagens desse tipo de pesquisa "[...] reside no fato de permitir ao investigador a cobertura de uma gama de fenômenos muito mais ampla do que aquela que poderia pesquisar diretamente" (GIL, 2010, p. 30).

$\mathrm{Na}$ sequência, foi realizada pesquisa documental a fim de analisar minuciosamente todos os trechos dos documentos que correspondem direta ou indiretamente sobre a formação continuada de gestores da Educação Básica. Os documentos selecionados foram: a Constituição Federal de 1988 (CF/88) - os artigos que competem a Educação Escolar-, a Lei de Diretrizes e Bases da Educação Nacional de 1996 (LDEBN/96), o Plano Nacional de Educação (2014-2024), as Diretrizes do Programa Nacional Escola de Gestores da Educação Básica (PNEGEB) e as Diretrizes do Programa Nacional de Fortalecimento dos Conselhos Escolares.

Com o intuito de obter maiores informações acerca do objetivo proposto, realizou-se também uma pesquisa de campo, pois conforme sinaliza Gonçalves (2001, apud, PIANA, 2009), esse tipo de metodologia objetiva buscar as informações diretamente com a população pesquisada, permitindo assim, um encontro mais direto com o objeto de pesquisa.

A pesquisa de campo foi efetivada por meio de entrevistas semiestruturadas a fim de obter uma amostragem mais abrangente, definiu-se que seriam realizadas as entrevistas com um gestor escolar de cada etapa de ensino da Educação Básica, bem como com o gestor educacional responsável pelas ações da Secretaria de Estadual de Educação (SED) no município de Naviraí, sendo um roteiro de entrevista para os gestores da educação básica e outro para o dirigente da secretaria de educação.

Para garantir o sigilo da identidade dos participantes, optou-se em denominar de sujeito A o gestor da educação infantil, B o gestor do Ensino Fundamental, C o diretor do Ensino Médio e D o responsável pelas atividades da secretaria estadual de educação no município.

Cabe salientar que o estudo aqui apresentado corresponde a um recorte do Trabalho de Conclusão de Curso, da graduação em Pedagogia. Está estruturado em dois 
momentos, sendo que o primeiro consiste nos aspectos teóricos que explicitam as transformações ocorridas no âmbito da gestão após a reforma do Estado, bem como uma breve análise das políticas de formação continuada de gestores da educação Básica. Na segunda etapa, encontra-se a análise dos dados obtidos na entrevista, bem como algumas considerações finais.

\section{A gestão escolar frente às novas incumbências do século XXI}

Com o advento das transformações políticas e econômicas que culminaram na Reforma do Estado, as políticas educacionais tenderam à qualidade e equidade educacional como novos objetivos para educação nacional, resultando assim, em novos paradigmas para escola e consequentemente à sua gestão (MACHADO, 2000). Diante disso, a administração escolar deixa de ser mera administração de recursos e agrega para si certa dose de filosofia e política, configurando-se em gestão escolar (DIAS, 2004).

Luck (2000) pondera que o conceito de gestão escolar supera a abordagem reducionista da administração, uma vez que recai à gestão da escola mobilizar recursos materiais e humanos, influenciar no clima organizacional da instituição fomentando a participação de todos no processo de tomada de decisões da escola, atuar como líderes pedagógicos acompanhando e avaliando os programas pedagógicos, bem como o resultado do desempenho dos alunos (LUCK, 2001).

Cabe salientar ainda que recai sobre o gestor escolar a responsabilidade de gerir o contexto escolar respeitando o princípio de gestão democrática determinada pela a LDBEN/1996, que corresponde a: "qualidade social da educação, o pluralismo de ideias e concepções pedagógicas, a gratuidade do ensino público, a participação das comunidades escolar e local, os conselhos escolares e as práticas que lhes são concernentes [...]" (GOMES, SANTOS, MELO, 2009, p. 266).

Desse modo, diante das novas exigências atribuídas ao cargo de diretor escolar se faz necessário o investimento no processo de formação desses profissionais, conforme pontua Luck (2000, p. 28-29):

O movimento pelo aumento da competência da escola exige maior competência de sua gestão, em vista do que, a formação de gestores escolares passa a ser uma necessidade e um desafio para os sistemas de ensino. Sabe-se que, em geral, a formação básica dos dirigentes 
escolares não se assenta sobre essa área específica de atuação e que, mesmo quando estes profissionais a têm, ela tende a ser livresca e conceitual, uma vez que esta é, em geral, a característica dos cursos superiores na área social.

Portanto, percebe-se que a atual filosofia de organização do trabalho no interior das escolas, bem como as demandas atuais da educação, exigem atitudes e habilidades específicas do cargo de gestor e que para seu preparo é necessário uma formação inicial e continuada sólida que atenda de fato às necessidades cotidianas das escolas.

\section{As políticas de formação continuada de gestores escolares na atualidade}

Considerando a especificidade do cargo de gestor escolar, nesta etapa, pretendese trazer à baila as orientações dos textos oficiais sobre a formação continuada de gestores da educação básica, tais como a CF/1988, LDBEN/1996 e a Lei 13.005, de 25 de junho de 2014, que aprova o Plano Nacional de Educação de 2014 (PNE).

Ao examinar a Carta Magna de 1988, nos artigos que competem à educação escolar (Art. 205 ao Art. 214) e a LDBEN/1996, verifica-se que aquela legislação não aborda as questões relativas à formação continuada de gestores da Educação Básica. A única menção direta que essa faz à formação dessa classe trabalhadora corresponde ao estabelecimento da formação inicial em graduação em Pedagogia ou em nível de pósgraduação para ingresso em cargos administrativos (BRASIL, 1996).

A LDBEN/96 não faz nenhum apontamento sobre a formação continuada em caráter específico para a função de diretor escolar, apenas de maneira geral englobando todos os profissionais da educação, desconsiderando as especificidades de cada função, conforme sinaliza o inciso II do artigo 67: "Os sistemas de ensino promoverão a valorização dos profissionais da educação, assegurando-lhes [...]: II aperfeiçoamento profissional continuado, inclusive com licenciamento periódico remunerado para esse fim [...]." (BRASIL, 1996, p. 48, grifos nossos).

No plano atual, PNE de 2014, evidencia-se por meio do discurso oficial maior atenção com a formação continuada dos profissionais da educação como um todo e não prioritariamente do corpo docente, conforme o plano anterior, uma vez que o texto oficial aborda na meta 16 o intuito em "[...] garantir a todos (as) os (as) profissionais da educação básica formação continuada em sua área de atuação, considerando as 
necessidades, demandas e contextualizações dos sistemas de ensino" (BRASIL, 2014, p. 80, grifos nossos).

Ainda que o PNE atual denote alguns avanços em relação ao plano anterior, o mesmo aborda com especificidade a formação de gestores apenas em uma de suas estratégias, ao demonstrar a necessidade de "desenvolver programas de formação de diretores e gestores escolares, bem como aplicar prova nacional específica, a fim de subsidiar a definição de critérios objetivos para o provimento dos cargos, cujos resultados possam ser utilizados por adesão" (BRASIL, 2014, p. 83).

Percebe-se que a formação continuada de gestores da educação básica é uma temática abordada, ainda que superficialmente, pelas legislações norteadoras da Educação Nacional, porém, encontram-se diversas lacunas nos textos oficiais, conforme apontado nos parágrafos anteriores, que deixam margem para diversas interpretações.

Diante dos expostos, buscou-se verificar na atualidade quais foram (e/ou são) os principais programas de formação de gestores da educação básica executado em âmbito nacional. Assim, o único programa específico de formação continuada para gestores, por ora localizado, foi o PNEGEB.

De acordo as Diretrizes Nacionais do PNEGEB, o objetivo central do Programa é o de “[...] contribuir com a formação efetiva de gestores educacionais da escola pública, de modo que disponham de elementos teórico-práticos que viabilizem uma educação escolar básica com qualidade social” (BRASIL, 2009, p. 6). E, para isso, o programa foi estruturado pelo Ministério da Educação (MEC) em três etapas, sendo que a primeira teve início em 2005, por meio de um projeto piloto, cuja carga horária era de 100 horas e objetivava atender 400 gestores; a segunda em 2006 obteve carga horária de 400 horas e pretensão de atendimento de 4.000 gestores e a terceira em 2009, projetouse o atendimento de 16.000 gestores, em curso de 180 horas.

Gomes, Santos e Melo (2009) fizeram um estudo aprofundado sobre o PNEGEB e os impactos desse em Pernambuco e verificaram que os cursos ofertados tinham certa dimensão prática ao solicitar a realização de determinados exercícios por meio de observações de campo, bem como tecer reflexões escritas embasadas nos conceitos estudados e nas observações realizadas. Esses autores também ponderaram a incapacidade do programa em alcançar todos os objetivos propostos, devido à maneira como estavam estruturados, pontuando assim a necessidade de alguns ajustes.

Além do PNEGEB, destaca-se o Programa Nacional de Fortalecimento dos Conselhos Escolares, que de acordo a Portaria Ministerial $\mathrm{n}^{\circ} 2.896 / 2004$, possui o 
objetivo de incentivar a criação e o fortalecimento dos Conselhos Escolares por meio de formação à distância, cujo público alvo engloba os diversos agentes sociais das escolas, principalmente o gestor escolar.

\section{Formação e tempo de atuação na docência e na gestão}

Os profissionais que contribuíram com a pesquisa possuem entre 17 a 28 anos de trabalho como educador e entre 8 a 12 anos como gestor escolar. Em relação à formação profissional o sujeito A possui formação no Magistério, Matemática, Normal Superior, Pedagogia e pós-graduação em Gestão Escolar. O sujeito B graduou-se em Pedagogia e pós graduou-se em Didática e Gestão Escolar. O sujeito C formou-se em Educação Artística e possui pós-graduação em Gestão Escolar. O sujeito D possui formação no magistério, Letras e especializou-se em linguística.

Ao analisar a formação dos envolvidos nas entrevistas, percebe-se pontos em comuns na formação inicial dos sujeitos A e B (pertencentes à Rede Municipal de Educação) que os capacita para atendimento do pré-requisito exigido pelo Artigo 64 da LDBEN/96, que determina: “A formação de profissionais de educação para administração, planejamento, inspeção, supervisão e orientação educacional para a educação básica, será feita em cursos de graduação em pedagogia [...].” (BRASIL, 1996, p. 37).

Além disso, encontra-se similaridade na formação continuada dos sujeitos A, B e C, sendo que esses pós graduaram-se em Gestão Escolar, porém, cabe salientar que tal similaridade se dá devido ao oferecimento dos cursos vinculados ao PNEGEB e que o ingresso nessa pós-graduação ocorreu depois de anos atuando como gestor escolar.

Em contrapartida, verifica-se que os sujeitos C e D (pertencentes à Rede Estadual de Educação), apesar de também ocuparem cargo de gestão (sendo um escolar e o outro educacional) possuem apenas formação inicial em disciplinas específicas; e, embora o sujeito C possua pós-graduação em gestão escolar, essa foi concluída somente após o ingresso na função atual, descumprindo assim um dos pré-requisitos estabelecidos pela LDBEN/96 para ocupação de tal cargo.

\section{Requisitos Fundamentais na Função de Gestor Escolar}


Ao serem questionados sobre os quesitos fundamentais na função de gestor escolar, o sujeito A considera que o aspecto essencial é: “[...] ter uma gestão [...] participativa [...] os pais serem muito bem tratados [...] porque nós dependemos da nossa família $[\ldots .$.$] tem muitas coisas que vão além do que a gente consegue ver, então a$ família que dá esse repasse pra nós do que tá acontecendo[...]”.

Já o sujeito B acredita que o fundamental é: “[...] ter um equilíbrio [...] ter um ambiente favorável ao trabalho [...] ter boas relações pessoais com [...] os funcionários, [...] pra que isso vá fluir lá na sala de aula com o aluno que é o nosso principal foco [...] ter confiabilidade $[. .$.$] pra esse público que você atende [. .]$.$" .$

O sujeito $\mathrm{C}$ aponta que o principal é "[...] ter o espírito de liderança, [...] saber ouvir, [...] ter muita paciência pra ouvir cada pessoa que nos procura e entender a posição da pessoa [...] ter harmonia com a sua equipe [...] tem que ter postura, tem que ter compromisso, tem que ter dedicação [...]" (grifo nosso). Já o sujeito D salienta que “[...] é liderança [...] o diálogo, respeito ao subordinado, estar aberto a novas [...] ideias, novos projetos" (grifo nosso).

Ao analisar as falas acima percebe-se que embora com palavras diferentes os sujeitos $\mathrm{A}$ e $\mathrm{B}$ vislumbram o estímulo à participação da comunidade escolar como uma possibilidade de auxílio no desempenho escolar dos discentes. E tal posicionamento vem ao encontro das ponderações de Luck (2000) quando sinaliza como uma das incumbências dos gestores escolares “[...] a mobilização dinâmica e coletiva do elemento humano [...] como condições básicas e fundamentais para a melhoria da qualidade do ensino [...]" (LUCK, 2000, p. 7).

Os sujeitos $\mathrm{C}$ e $\mathrm{D}$ ao apontarem que os quesitos fundamentais para a função do gestor escolar é o espírito de liderança e o saber ouvir, demonstram claramente uma das similaridades em suas perspectivas em relação a essa questão. Na sequência de suas falas, percebe-se que ambos possuem uma visão mais gerencial, técnica e administrativa de condução das atividades da instituição de ensino.

Nota-se que todos os pontos elencados pelo sujeito C estão relacionados, apenas, às ações executáveis pelo diretor escolar, ou seja, em nenhum momento de sua fala deixa transparecer como um dos quesitos primordiais na função do gestor escolar a participação dos demais atores, percebe-se uma visão mais centralizadora na condução das atividades.

Nessa direção, verifica-se que o sujeito D comunga do mesmo princípio, visto que mesmo dizendo que o gestor "[...] deve estar aberto a novas [...] ideias, novos 
projetos", não sinaliza em nenhum momento de sua fala a preocupação em articular estratégias de trabalho que mobilizem os segmentos da escola no desenvolvimento de ações que possam contribuir no desempenho dos discentes. Além disso, percebe-se um tom antidemocrático ao empregar o termo "subordinados" ao tratar dos demais agentes escolares.

Assim, percebe-se que o único ponto em comum entre os quatro participantes se refere à relevância de ter um bom relacionamento com os colaboradores da instituição de ensino, embora abordarem de maneira diferente. Contudo, verifica-se que há uma enorme diferença de perspectiva entre os gestores do município e os do estado, visto que os primeiros possuem uma visão de gestão participativa em que o foco consiste em criar estratégias para alcançar o desempenho efetivo dos discentes, em contrapartida aos do estado que não denotam tal consideração e estão mais centrados em apenas liderar e não gerir.

\section{Mecanismos que auxiliam na gestão}

$\mathrm{Na}$ sequência das entrevistas os sujeitos foram questionados a respeito dos mecanismos que auxiliam na gestão escolar, se existem, e se sim, quais são. Então, obteve-se a seguinte resposta do sujeito A: "[...] esses mecanismos, por exemplo, a gerência tem toda uma tipologia que dependendo da tipologia que você é dentro da escola você tem a quantidade de funcionário X, essa é uma forma que a gerência [...] achou de nos auxiliar".

Seguindo a mesma direção em apontar mecanismos oriundos do Sistema Educacional, o sujeito $\mathrm{B}$ considera que a própria legislação ao instituir a gestão participativa com os conselhos escolares e as Associações de Pais e Mestres já determinou um auxílio aos gestores nas tomadas de decisões e nisso reside um mecanismo de ajuda aos gestores escolares.

Diferentemente dos participantes $\mathrm{A}$ e $\mathrm{B}$, o sujeito $\mathrm{C}$ sinaliza que "[...] não tem nenhum mecanismo de auxílio [...]." Já o Sujeito D, pontua as tecnologias da informação e comunicação, os resultados das avaliações internas e externas, pois denotam as dificuldades e avanços da escola, bem como as experiências vividas por outras instituições que podem servir como exemplo às demais. 
Ao observar as respostas dos sujeitos acima citados, percebe-se certa similaridade nas respostas dos sujeitos A, B e D, embora esses não apontem exatamente os mesmos mecanismos de auxílio, mas apontam recursos de origem externa que podem ofertar suporte à gestão escolar.

Quando o sujeito B sinaliza como principal mecanismo de apoio os demais grupos consultivos formados dentro da escola, tais como Conselho Escolar e Grêmio Estudantil, nota-se que tal embasamento provém do que determina a própria LDBEN/96, conforme citado anteriormente neste trabalho, em relação à instituição da gestão democrática. Além disso, a mesma determina a criação de conselhos escolares e demais grupos que auxiliem nas tomadas de decisões.

$\mathrm{Na}$ sequência das entrevistas, considera-se relevante a ponderação feita pelo sujeito D ao apontar as avaliações como aspectos que oferecem suporte ao gestor no planejamento de suas ações, pois conforme sinaliza Luck (2000) recai sobre o diretor, além de todas as responsabilidades, planejar a organização dos trabalhos, bem como lidar com a avaliação dos resultados.

Contudo, embora os resultados das avaliações sejam de extrema relevância para delinear o nível de ensino, cabem alguns questionamentos passíveis de estudos, tais como: será que os gestores das escolas públicas do Brasil têm tido acesso a esses dados? E, se tem, será que sabem explorá-los a fim de criar estratégias que alavanquem o ensino das instituições escolares?

Quando o sujeito $\mathrm{C}$ afirma não haver nenhum mecanismo de auxílio à gestão escolar, demonstra falta de conhecimento a respeito de elementos básicos que subsidiam a condução das atividades dentro das instituições de ensino, dadas pela própria legislação, tais como a instituição da participação de todos na construção do Projeto Político Pedagógico e formação de Conselhos Escolares, feita pela LDBEN/96. No entanto, considera-se que tal afirmação aponta a ausência de políticas públicas que tenham como escopo o suporte para a gestão da escola.

\section{Política de Formação Continuada}

Dando continuidade às entrevistas, os sujeitos foram questionados a respeito da existência de política de formação continuada para gestores da Educação Básica. 
Diante disso o sujeito A respondeu afirmativamente a esse questionamento sinalizando o PNEGEB como a capacitação ofertada.

Já o sujeito B pondera que "Não digo que existe assim uma política em si, existe os cursos da escola de gestores [...] e outros cursos que você vai pegando uma carona, em seminários, congressos [...] que traz uma mensagem boa que ajuda na gestão [...]”.

Na mesma direção do sujeito B, o participante C afirma que: "Há uma certa política, mas bem [...] pouco ativa”. Já o sujeito D faz o seguinte apontamento no intuito de responder a essa questão:

\begin{abstract}
A Secretaria de Educação ela tem um [...] curso de gestão que é [...] on line [...] com encontros periódicos, [...] também a gente tem cursos que são feitos através de web conferências e capacitações que são feitas na própria escola. [...] também a Secretaria de Educação trabalha muito na formação técnica do gestor [...] na gestão financeira da escola, [...] Hoje a escola além de trabalhar na questão de administração financeira da compra, prestação de contas, nós também agora estamos assumindo a questão da folha de pagamento dos professores e administrativo, então a responsabilidade do gestor aumentou muito nos últimos anos, nós temos visto crescendo a cada dia e pra que o gestor possa desempenhar bem a essa função, ele precisa tá bem formado [...].
\end{abstract}

Ao analisar as respostas acima, percebe-se que todos os sujeitos apontam que há certo investimento em formação continuada de gestores, embora o sujeito B, não reconheça que nisso consista exatamente uma política de formação continuada. Nota-se, também, que para os sujeitos A, B e C o único programa específico para área ofertado até hoje está relacionado ao PNEGEB.

Já o sujeito D faz uma afirmação um pouco diferente dos demais participantes, pois pontua web conferências e capacitações na própria escola, além da pós-graduação em gestão escolar ofertada pela escola de gestores. Contudo, a partir dessa afirmação surge certa divergência no repasse das informações, pois aparece apenas na fala do último sujeito, ao passo que os demais não fizeram nenhuma sinalização correspondente.

Além disso, as falas dos sujeitos A, B e C vêm ao encontro das considerações do tópico anterior deste trabalho ao trazer à tona a relevância dada à formação continuada de gestores da Educação Básica pelos documentos oficiais que repercutiu em apenas um programa específico para a formação continuada dos mesmo que consiste no PNEGEB, sinalizado por todos. 
Considera-se que o sujeito D possa ter se equivocado e confundido política de formação continuada com treinamentos para a execução de determinadas função administrativas, que consiste em informações pontuais e técnicas para a realização de tais serviços como a elaboração da folha de pagamento e prestação de contas, conforme o mesmo pontua como atividades inerentes à função do gestor escolar.

\section{Participação em Formação Continuada}

$\mathrm{Na}$ sequência das entrevistas os participantes $\mathrm{A}, \mathrm{B}$ e $\mathrm{C}$ foram questionados a respeito da quantidade de formações continuadas específicas para a área de gestão escolar que participaram. Para o sujeito D não foi realizado tal questionamento, pois esse ocupa o papel de gestor educacional, e o foco desta pesquisa consiste na formação continuada de gestores escolares.

O sujeito A que está há mais de 10 anos na direção escolar, sinaliza apenas o: “[...] curso de gestão escolar pela escola de gestores [...]". Na oportunidade o mesmo ainda enfatiza a ausência desse tipo de incentivo, porém, percebe-se a tentativa de atenuar tal realidade ao tecer a seguinte consideração: “[...] nós não temos formação,

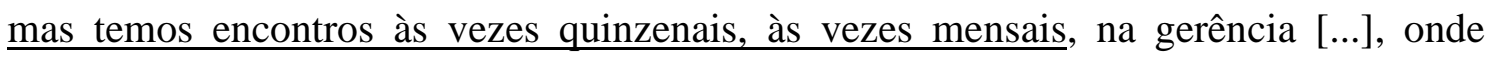
chegou uma Lei nova da Educação Infantil ela ${ }^{5}$ repassa [...] é um jeito da gente sempre tá a par [...] (grifos nossos).

Em consonância com o entrevistado anterior, o sujeito B afirma que as únicas formações que participou correspondem aos “[...] cursos da escola de gestores [...] fora isso só as pós-graduações que fiz daí por conta própria e tudo isso que a gente participa na educação $[\ldots . . . "$

Similarmente aos demais entrevistados, o sujeito C pontua o PNEGEB como uma das formações que participou, porém sinaliza a participação em uma capacitação correspondente à função de gestor escolar realizada na capital do estado com duração de uma semana e que além dessas duas oportunidades ela nunca recebeu outras a não ser como reuniões de trabalhos que tratam de assuntos pontuais e específicos na área.

As considerações feitas pelos três participantes denotam, mais uma vez, a ausência de investimento em formação específica para o cargo de gestor escolar e que a

${ }^{5}$ Refere-se à coordenadora de área do município responsável pela Educação Infantil. 
única capacitação ofertada pelos órgãos governamentais está ligada ao PNEGEB. Notase que o sujeito $\mathrm{C}$ teve uma oportunidade a mais que os demais, porém, talvez tal singularidade se restrinja a ele por ser uma oferta da Secretaria Estadual de Educação e os demais sujeitos sejam pertencentes à Rede Municipal de Ensino (REME).

Embora o sujeito A esteja vinculado à REME e o sujeito C à SED, percebe-se que determinadas práticas são similares conforme os encontros periódicos para repassam atualizações e normativas para a educação. Cabe ressaltar que mesmo não se encaixando como uma formação continuada propriamente dita, tal iniciativa é de grande relevância, uma vez que demonstra a tentativa de empregar o princípio de gestão democrática, disseminando as informações aos envolvidos nos processos educacionais.

Considerando a diversidade de atribuições que recai ao gestor escolar cabe o seguinte questionamento: como esses conseguirão desempenhar com excelência tais atribuições se muitos não obtiveram embasamento suficiente em suas respectivas formações iniciais e a oferta de formações continuadas tem sido escassa?

Diante disso, pode-se dizer que são muitas as expectativas lançadas sobre a educação escolar na atualidade e, segundo Luck (2000), conforme a exigência sobre escola aumenta, proporcionalmente aumenta a cobrança de sua gestão, tornando-se necessário o investimento em formação continuada para atender às demandas, visto que a formação inicial parece não ser suficiente.

\section{Avaliações das Formações}

Em continuidade às entrevistas todos os sujeitos, exceto o sujeito $\mathrm{D}$, foram questionados acerca da avaliação que tecem sobre as formações de que participaram. O participante A considera como positivas as capacitações que participou. Já o sujeito B acredita que embora tenha sido à distância foi positiva a capacitação que participou, porém como foi a primeira edição houve alguns impasses devido a troca frequente de orientadores, além disso, considera que há muita teoria. Em contrapartida o sujeito $\mathrm{C}$ não fez nenhum apontamento de aspectos negativos.

Mediante as avaliações feitas pelos participantes, considera-se positivamente o desenvolvimento dos cursos, embora o sujeito B tenha sinalizado alguns impasses ao longo da realização do mesmo. 
Conforme sinalizado no estudo feito em 2008 sobre o PNEGEB por Gomes, Santos, Melo (2009), o programa teve algumas lacunas e careciam de ser preenchidas. No entanto, percebe-se que há a possibilidade de que os aspectos negativos sinalizados pelo sujeito B tenham sido superados, visto que esse realizou o curso na primeira etapa, e os demais sujeitos em edições posteriores, talvez por isso estes não fizeram nenhum apontamento similar.

\section{Contribuição da formação que participou}

Na sequência os sujeitos $\mathrm{A}, \mathrm{B}$ e $\mathrm{C}$ foram questionados se houve contribuição das formações que participaram para o seu cotidiano. O último entrevistado foi questionado sobre as contribuições para os gestores, em sua perspectiva. Diante daquela indagação o sujeito A pontuou que: “[...] nesses encontros [...] é a hora que a gente tem pra poder falar os problemas que estão acontecendo [...] e que às vezes a gente fica sem saber o que fazer e é uma coisa assim a gente precisa escutar uma outra opinião [...] pra tentar resolver nossos problemas dentro da escola $[\ldots] "$.

Diferentemente da perspectiva do sujeito A, o entrevistado B sinaliza que: “[...] valeu muito apena essas formações. [...]”, porém aponta a ausência de investimento em cursos específicos para área, uma vez que a maioria é “[...] de forma geral pra Educação Infantil [...] pra alfabetização [...] que o gestor acaba pegando uma carona e tirando muito proveito porque o gestor não é só administrador ele é pedagógico [...]”.

Assim como o sujeito A, o sujeito $\mathrm{C}$ sinaliza positivamente a oportunidade de troca de experiência com os demais participantes dessas formações. Além disso, esse entrevistado aponta que a aquisição de conhecimentos a respeito das bases legais foram de importância, pois de acordo com ele: "Eu não posso administrar uma escola se não tiver embasamento legal, eu tenho que saber o que eu posso ou não fazer".

Divergentemente dos demais entrevistados, o Sujeito D aponta que a SED tem se empenhado na formação de gestores, pois até os interessados em se candidatar aos cargos de diretor, vice-diretor e coordenador pedagógico precisam passar por uma formação e só após a conclusão com êxito poderá se candidatar.

Diante das considerações feitas pelos sujeitos entrevistados acerca da contribuição dos cursos de formação continuada para gestores da Educação Básica, percebe-se que embora com alguns destaques diferentes os participantes A e C 
reconhecem que um dos aspectos relevantes dessas formações corresponde à troca de experiência; em ouvir o outro, ou seja, embora implicitamente, eles reconhecem que não detém todo o conhecimento sobre o cargo que ocupam e nisso consiste a necessidade de momentos de formação como aquele que traz novas concepções aos participantes.

Além disso, nas falas do sujeito $\mathrm{C}$, verifica-se que essas oportunidades podem contribuir para aquisição de conhecimentos elementares que norteiam a educação pública, visto que existem diretores que não possuem a formação em Pedagogia (curso que é considerado a base para a formação de gestores escolares).

Em contrapartida o sujeito B, embora pontue que tal iniciativa governamental tenha contribuído com a sua prática cotidiana, também enfatiza a carência desse tipo de investimento, logo, subentende-se que a ausência da oferta de formação continuada tem feito falta para o desempenho do gestor na atualidade.

O sujeito $\mathrm{D}$, outra vez tem um posicionamento divergente dos demais e sinaliza informações que não são possíveis constatar, pois ao afirmar que a SED tem se empenhado para a formação dos gestores, torna-se incompreensível os apontamentos realizados pelos demais participantes ao longo das entrevistas que sinalizam a ausência desse tipo de formação. Além disso, o site da SED não faz nenhum apontamento de oferta de cursos específicos para gestão recentemente.

Diante dos expostos, nota-se que as capacitações ofertadas aos gestores escolares contribuiriam significativamente para o desempenho de suas funções. No entanto, a carência de oferta consiste na queixa dos diretores e na necessidade de capacitar essa categoria profissional para que assim consiga atingir os objetivos que estão propostos para a educação.

\section{Dificuldade e Desafio na Atuação dos Gestores}

O último questionamento feito aos sujeitos foi a respeito das dificuldades e desafios na atuação dos gestores escolares, em que o sujeito A sinaliza a dificuldade em atendar a demanda de vagas na Educação Infantil.

Para o sujeito B as dificuldades e desafios na atuação do gestor escolar correspondem ao saber lidar com a diversidade social presente no contexto escolar, bem como os problemas que cada um traz para dentro da escola, inclusive problemas de saúde grave que algumas crianças apresentam (neurológicos e psicológicos) que a 
família não percebe e resta à escola estar atenta a essas questões e informar aos responsáveis.

Já o sujeito $\mathrm{C}$ encara a sobrecarga de atividades como o maior entrave para o desempenho de sua função, principalmente a junção das atividades administrativas e pedagógicas sob responsabilidade do gestor escolar, pois de acordo com esse entrevistado a gestão escolar deveria contar com dois gestores, sendo um para tratar das atividades pedagógicas e outro das incumbências administrativas.

Para responder esse questionamento, o sujeito D pontua que há certa falta de motivação por parte dos trabalhadores em educação e isso se reside em um desafio para a gestão, bem como a violência dentro das escolas.

Ao analisar as respostas de cada participante, verifica-se que não há similaridade em nenhuma das respostas, sendo muito singulares. No entanto, acredita-se que tal fenômeno ocorra devido a cada gestor analisar o mesmo questionamento a partir de sua realidade, visto atuaram em um nível educacional diferente, e em cada etapa de ensino reside sua particularidade.

Sendo assim, quando o sujeito A aponta a demanda por vagas como um das dificuldades do cotidiano e que impacta no desempenho de suas funções, pode-se considerar a relação das políticas públicas com os agentes incumbidos de efetivá-las, visto que a demanda por vagas em instituições de Educação Infantil tem representado um grande desafio para o poder público, uma vez que o acesso a essa etapa de ensino passou a ser direito subjetivo de todas as crianças.

Os apontamentos realizados pelo sujeito B são importantes, pois sinalizam que os fatores sociais têm interferido rigorosamente no desempenho educacional dos discentes e que incumbe às instituições de ensino dar respostas a essa problemática. Contudo, por meio da fala do sujeito B, percebe-se que a escola não tem preparo para lidar com essas questões e ainda carece maior atenção do poder público em subsidiar ações que contribuam para a reflexão e direcionamento dos agentes educacionais para a superação desses desafios.

O sujeito $\mathrm{C}$ ao sinalizar a sobrecarga de atividades atribuídas ao diretor escolar e a ideia de desmembrar as tarefas administrativas e pedagógicas demonstra certo desconhecimento da história/fundamentos da gestão escolar, uma vez que o conceito de gestão substitui os princípios da simples administração escolar, devendo haver a articulação entre as atividades administrativas e pedagógicas pelo diretor escolar (DIAS, 2004). Sendo assim, embora a consideração realizada pelo sujeito C seja relevante, pois 
é a opinião que possui a respeito do questionamento feito, é fato que ambas as atribuições são inerentes ao cargo de gestor.

Em relação à resposta do sujeito $\mathrm{D}$, analisa-se que as questões relacionadas a desmotivação profissional é uma constante em quase todas as profissões e organizações do mundo, podendo impactar negativamente no desempenho dos agentes escolares. Nesse sentido o investimento em formação dos gestores escolares poderia contribuir com esta e outras questões, uma vez que é responsabilidade o gestor incentivar a criação de clima e cultura organizacional positivo, porém, não será possível a realização de tal tarefa, se os responsáveis não possuírem conhecimento específico que os auxilie nesse processo.

\section{Considerações finais}

Com o advento das transformações políticas e econômicas que permearam o século XX o conhecimento tornou-se força produtiva direta. Diante disso, recaiu-se às instituições escolares a incumbência em formar o cidadão ideal para essa nova sociedade que se formava sob as bases do capitalismo contemporâneo.

Influenciado por esse contexto social, a administração escolar foi substituída por uma nova filosofia de condução dos trabalhos educativos definido como gestão escolar. A essa denominação incorporou-se certa dose de filosofia e política que outrora não era encontrada no conceito de administração, uma vez que agora recai sobre a função de gestor escolar tanto os aspectos administrativos como pedagógicos da escola.

Nota-se que conforme a exigência sobre a educação institucionalizada aumenta, proporcionalmente, eleva-se o nível de cobrança sobre sua gestão, tornando-se imprescindível o investimento em formação continuada, visto que os conhecimentos contidos na formação inicial são insuficientes para formar o gestor escolar que atenda as demandas da sociedade.

Mediante a necessidade em investimento formativo para essa categoria profissional, buscou-se ao longo desta pesquisa relacionar as políticas de formação continuada de gestores da Educação Básica com o atendimento das demandas do cotidiano escolar. E, por meio da análise de todo o material coletado, verificou-se que a preocupação com essa questão ainda não é uma constante para os órgãos governamentais, visto que não há uma política efetiva de formação continuada para 
gestores da Educação Básica, pois existe apenas um programa nacional voltado especificamente para essa questão, contudo, não está sendo sistematicamente ofertado e, portanto, não acessível a todos que estão à frente da gestão.

As falas dos participantes do estudo demonstram, em vários momentos, a ausência e a necessidade iminente do investimento nessa área, pois conforme sinalizaram são diversas as atribuições do gestor escolar e torna-se impossível conduzir com maestria o conjunto de atividades, visto que não possuem embasamento sólido para tal.

Diante dos expostos, acredita-se que o investimento na formação dos gestores da Educação Básica seja uma das estratégias fundamentais a ser efetivada na luta por uma educação de qualidade, visto que esse profissional está na condução dos trabalhos das instituições de ensino e precisam estar bem formados e informados para que consigam contribuir da melhor maneira na construção de educação de qualidade.

Além do investimento por parte dos órgãos governamentais em formação continuada para gestores da Educação Básica, é imprescindível que no meio acadêmico haja estudos voltados para essa questão, visto que há poucas pesquisas nessa área, e a academia também tem o dever de contribuir para a melhoria da educação.

\section{Referências}

BRASIL. Lei n. ${ }^{\circ} 9.394$ de 20 de dezembro de 1996. Estabelece a Lei de Diretrizes e Bases da Educação Nacional (LDBEN). Brasília, 1996. Disponível em: < https://www2.senado.leg.br/bdsf/bitstream/handle/id/70320/65.pdf?sequence=3> Acesso em 04 abr. 2015.

BRASIL. Lei 13.005, de 25 de junho de 2014. Aprova o Plano Nacional de Educação PNE, e dá outras providências. Brasília, DF: Câmara dos Deputados, 2014. Disponível em: $<$ http://www.observatoriodopne.org.br/uploads/reference/file/439/documentoreferencia.pdf >. Acesso em: Acesso em: 20 abr. 2015.

BRASIL. Diretrizes Nacionais do Programa Escola de Gestores da Educação Básica Pública. Brasília/DF: Ministério da Educação (MEC), 2009. Disponível em: < http://portal.mec.gov.br/index.php?option=com_docman\&view=download\&alias=879diretrizes-n-pdf\&Itemid=30192>. Acesso em: 31 de mar de 2015.

DIAS, J. A. Gestão da Escola. In: MENESES, J. G. C (et al). Estrutura e Funcionamento da Educação Básica. São Paulo: Pioneira Thomson, 2004. 
GIL, A. C. Como Elaborar Projetos de Pesquisa. 5 ed. São Paulo: Atlas, 2010.

GOMES, A.; SANTOS, A. L. F. dos; MELO, D. B. L. de. Escola de Gestores: política de formação em gestão escolar. Revista Brasileira de Política e Administração da Educação, Goiânia/GO, v.25, n.2, mai./ago., p. 263-281, 2009. Disponível em: < seer.ufrgs.br/rbpae/article/download/19496/11321>. ISSN 1678-166X. Acesso em: 08 mar. 2015.

LUCK, H. Perspectivas da Gestão Escolar e Implicações Quanto à Formação de Seus Gestores. Em Aberto, Brasília/DF, v. 17, n. 72, fev./jun., p. 11-33, 2000. Disponível em: <http://lms.ead1.com.br/upload/biblioteca/curso_4392/fron00lbi6.pdf>. ISSN: 2176-6673. Acesso em: 26 mar. 2015.

LUCK, H. A Escola Participativa: o trabalho do gestor escolar. 5 ed. Rio de Janeiro: DP\&A, 2001. p. 13-27.

MACHADO, M. A. de M.. Desafios a Serem Enfrentados na Capacitação de Gestores Escolares. Em Aberto. Brasília, v. 17, n 72, fev./jun., p. 97-112, 2000.

PIANA, M. C. A Construção do Perfil do Assistente Social do Cenário Educacional [online]. São Paulo: Editora UNESP; São Paulo: Cultura Acadêmica, 2009. 167-210 p. Disponível em: <http://books.scielo.org/id/vwc8g/pdf/piana-9788579830389-06.pdf>. ISBN 978-85-7983-038-9. Acesso em: 10 agos. 2015.

QUARESMA, V. B.; JUREMA, S. Aprendendo a Entrevistar: como fazer entrevistas em Ciências Sociais. Revista Eletrônica dos Pós-Graduandos em Sociologia Política da UFSC, Santa Catarina/Brasil, v. 2, no 1 (3), jan.-jul., p. 68-80, 2005. Disponível em: <http://ftp.unisc.br/portal/upload/com_arquivo/1386353091.pdf>. ISSN 18065023. Acesso em: 11 ago. 2015.

\section{Como referenciar este artigo}

RODRIGUES, Evally Solaine de Souza; REIS, Maria das Graças Fernandes de Amorim dos; ARANDA, Maria Alice de Miranda. A formação continuada para gestores da educação básica e a demanda do cotidiano escolar: uma análise no âmbito das políticas públicas. Revista on line de Política e Gestão Educacional, Araraquara, v.20, n.03, p. 444-462, 2016. Disponível em: <http://dx.doi.org/10.22633/rpge.v20.n3.9722>. ISSN: 1519-9029.

Submetido em: junho/2016

Aprovado em: agosto/2016 